\title{
Micro Light Plates for Photoactivated Micro-Power Gas Sensors ${ }^{+}$
}

\author{
Olga Casals 1, Nicolai Markiewicz 1,2,3, Cristian Fabrega 1, Isabel Gràcia 4, Carles Cané 4, \\ Hutomo Suryo Wasisto 2,3, Andreas Waag 2,3 and J. Daniel Prades 1,* \\ 1 MIND-IN2UB, Department of Electronic and Biomedical Engineering, Universitat de Barcelona, \\ E-08028 Barcelona, Spain; ocasals@el.ub.edu (O.C.); n.markiewicz@tu-braunschweig.de (N.M.); \\ cfabrega@el.ub.edu (C.F.) \\ 2 IHT-LENA, Technische Universität Braunschweig, Braunschweig, D-38106, Germany; \\ h.wasisto@tu-braunschweig.de (H.S.W.); a.waag@tu-braunschweig.de (A.W.) \\ 3 Epitaxy Competence Center $\left(\mathrm{ec}^{2}\right)$, Technische Universität Braunschweig, 38106 Braunschweig, Germany \\ 4 IMB-CNM (CSIC), Institut de Microelectrònica de Barcelona, E-08193 Cerdanyola del Vallès, Spain; \\ isabel.gracia@imb-cnm.csic.es (I.G.); carles.cane@imb-cnm.csic.es (C.C.) \\ * Correspondence: dprades@el.ub.edu \\ + Presented at the 8th GOSPEL Workshop. Gas Sensors Based on Semiconducting Metal Oxides: Basic \\ Understanding \& Application Fields, Ferrara, Italy, 20-21 June 2019.
}

Published: 19 June 2019

\begin{abstract}
In this contribution we present a highly miniaturized device that integrates a photoactive material with a highly efficient LED light source. This so-called micro light plate configuration $(\mu \mathrm{LP})$ allows for maximizing the irradiance impinging on the photoactive material, with a minimum power consumption, excellent uniformity and accurate control of the illumination. We demonstrate that, with the $\mu \mathrm{LP}$ approach, very efficient low power gas sensors can be built, and provide a detailed analysis of the rationales behind such improvement, as well as a quantitative model and a set of design rules to implement it in further integrated applications. As a demonstrator, we will describe a $\mathrm{NO}_{2}$ gas sensor operating in the part per billion range $(\mathrm{ppb})$ with microwatt $(\mu \mathrm{W})$ power consumption. These are the best figures reported to date in conductometric metal-oxides (MOX) sensors operated with light (instead of heat) at room temperature.
\end{abstract}

\section{Motivation}

Conventional conductometric MOX-based gas sensors operate at relatively high temperatures (few hundred ${ }^{\circ} \mathrm{C}$ ) to activate the interaction between the target gas molecules and the sensor material. This leads to important power needs, with values of $\sim 10 \mathrm{~mW}$ for the most optimized/miniaturized "micro-hot-plate" configurations [1]. Light is known as an alternative path to achieve such activation [2], but most implementations to date are bulky and based on discrete components, lacking power efficiency and optimized irradiance/response ratios (Figure 1a). Here, we present the new "micro-light-plate" ( $\mu \mathrm{LP}$ ) approach [2]: a sensor configuration built around a miniaturized LED (Figure 1a). This represents one of the few efforts made to date to produce wafer-scale integrated illuminated sensors [3,4], and the one rendering the best performances, by more than 3 orders of magnitude (from tens of $\mathrm{mW}$ to tens of $\mu \mathrm{W}$ ) [5]. 

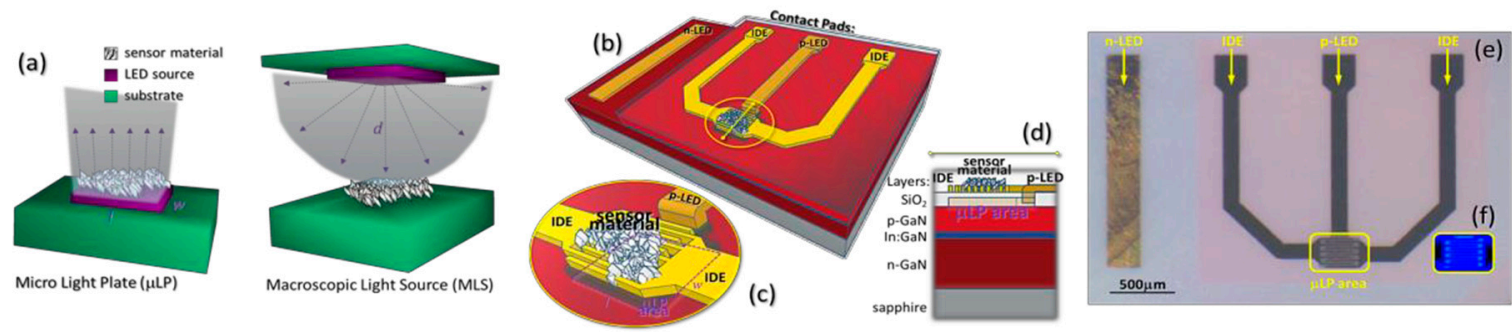

Figure 1. (a) Comparison between the Micro Light Plate $(\mu \mathrm{LP})$ proposed in this work and the conventional light spreading scenario (Macroscopic Light Source). (b) Schematic view of the $\mu$ LP devices. (c) Detailed view of the $\mu \mathrm{LP}$ area containing the active LED region, the IDEs, and the sensor material. (d) Cross section of the device structure across the $\mu$ LP area. (a-d) Adapted from Ref. [2], with the permission of AIP Publishing. (e) Optical microscopy image of the actual $\mu$ LP devices as fabricated, and (f) with the LED lit on.

\section{Methods}

In the $\mu \mathrm{LP}$ (Figure $1 \mathrm{~b}-\mathrm{d}$ ), the sensor material is placed directly on top of a planar LED structure (InGaN, $455 \mathrm{~nm}$ peak emission), only separated by a few hundred nanometers ( $350 \mathrm{~nm}$ ) to insulate it electrically $\left(\mathrm{SiO}_{2}\right)$. Consequently, almost all the light emitted by the LED impinges on the sensor MOX, allowing for very well controlled, uniform and high irradiances, with reduced electrical power consumption. For demonstration purposes, the sensor material we choose were $\mathrm{ZnO}$ nanoparticles deposited on the $\mu \mathrm{LP}$ on top of a pair of Interdigitated Electrodes (IDE) made of Au (Figure 1b-f). Theory showed that, in order to achieve an optimum performance in terms of power consumption, the LED emission area must match the area of the sensor material (in size and shape). In our case, the active area was a rectangle of $190 \mu \mathrm{m} \times 250 \mu \mathrm{m}$.

\section{Results}

Figure 2a shows an example of the resistance records measured in the presence of $\mathrm{NO}_{2}$ in increasing concentrations, from $25 \mathrm{ppb}$ to $1 \mathrm{ppm}$. Figure $2 \mathrm{~b}$ summarizes the responses obtained under different irradiance levels, showing a complex bell-shaped response that is fully explained by the balance between the adsorption and desorption of oxidizing molecules from the surface by the action of the impinging photons [6]. Remarkably, at the lowest concentrations investigated, responses above $20 \%$ were obtained, with just $30 \mu \mathrm{W}$ of electrical power applied to the LED in the $\mu \mathrm{LP}$. At the optimum irradiance levels, peak responses of more than $90 \%$ to $25 \mathrm{ppb}$ were found. In these conditions, with a noise-to-signal level of $3 \%$, even concentrations below 1 ppb could theoretically be detected.
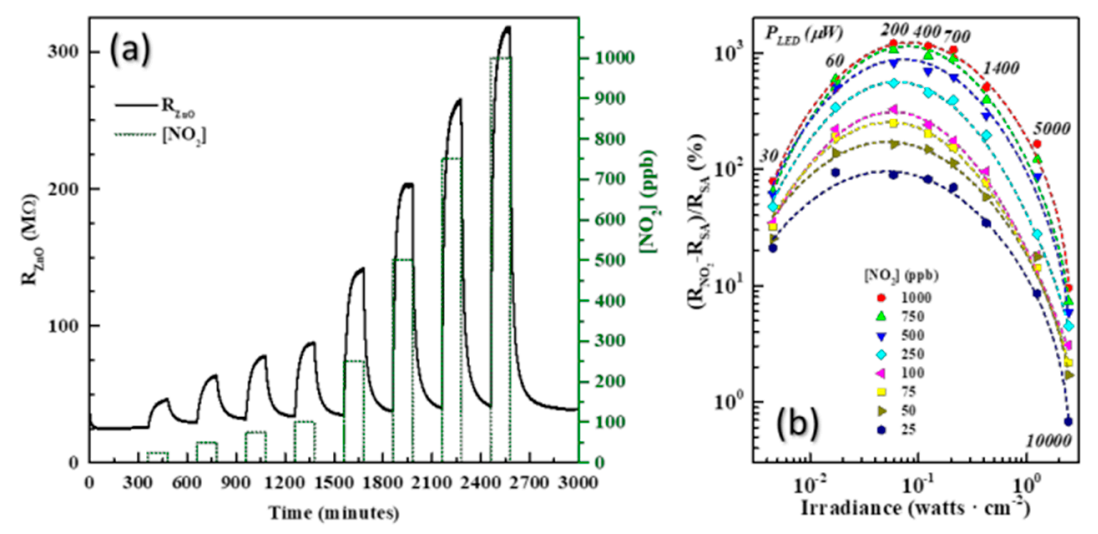

Figure 2. (a) Resistance record of the response to $\mathrm{NO}_{2}$ and (b) summary of the responses obtained under different irradiance levels (and thus power consumption). Electrical power applied to the LED at each irradiance level is indicated in italics labels. Lines corresponds to qualitative fittings to existing models in the literature [6]. Data taken from Ref. [5]. 


\section{References}

1. Elmi, I.; Zampolli, S.; Cozzani, E.; Mancarella, F.; Cardinali, G.C. Development of ultra-low-power consumption MOX sensors with ppb-level VOC detection capabilities for emerging applications. Sens. Actuators B Chem. 2008, 135, 342.

2. Prades, J.D.; Wasisto, H.S.; Markiewicz, N.; Cané, C.; Fabrega, C.; Waag, A.; Casals, O.; Gràcia, I. Micro light plates for low-power photoactivated (gas) sensors. Appl. Phys. Lett. 2019, 114, 053508.

3. Espid, E.; Taghipour, F. UV-LED Photo-activated Chemical Gas Sensors: A Review. Crit. Rev. Solid State Mater. Sci. 2017, 42, 416.

4. Wang, C.Y.; Cimalla, V.; Kups, T.; Röhlig, C.C.; Stauden, T.; Ambacher, O.; Kunzer, M.; Passow, T.; Schirmacher, W.; Pletschen, W.; et al. Integration of $\mathrm{In}_{2} \mathrm{O}_{3}$ nanoparticle based ozone sensors with GaInN/GaN light emitting diodes. Appl. Phys. Lett. 2007, 91, 1.

5. Casals, O.; Markiewicz, N.; Fabrega, C.; Gracia, I.; Cané, C.; Wasisto, H.S.; Waag, A.; Prades, J.D. A Parts Per Billion (ppb) Sensor for $\mathrm{NO}_{2}$ with Microwatt $(\mu \mathrm{W})$ Power Requirements based on Micro Light Plates. ACS Sens. 2019, 4, 822.

6. Prades, J.D.; Jimenez-Diaz, R.; Manzanares, M.; Hernandez-Ramirez, F.; Cirera, A.; Romano-Rodriguez, A.; Mathur, S.; Morante, J.R. A model for the response towards oxidizing gases of photoactivated sensors based on individual $\mathrm{SnO}_{2}$ nanowires. Phys. Chem. Chem. Phys. 2009, 11, 10881.

(C) 2019 by the authors. Licensee MDPI, Basel, Switzerland. This article is an open access article distributed under the terms and conditions of the Creative Commons Attribution (CC BY) license (http://creativecommons.org/licenses/by/4.0/). 